\title{
Estudo comparativo entre duas técnicas de ataque ácido na cerâmica, para cimentação de bráquetes: estudo in vitro
}

\section{Comparative study between the techniques of acid etching in ceramics, for cementation of brackets: in vitro study}

\section{Estudio comparative entre dos técnicas de ácido en cerámica, para cementación de brackets: estudio in vitro}

Patricio Quintana iD

Endereço para correspondência:

Patricio Quintana

Faculdade do Centro Oeste Paulista - FACOP

Rua Luiz Gimenez Mocegose, 72

Distrito Industrial

17499-010 - Piratininga - São Paulo - Brasil

E-mail: clinicakristaldent@yahoo.es

Recebido: 23.07 .2020

Modificado: 10.08.2020

Aceito: 21.08.2020

\section{RESUMO}

O objetivo desta pesquisa in vitro é descobri qual o melhor método de condicionamento ácido em superfícies de porcelana feldspática, que permitem melhor adesão aos bráquetes utilizando ácido fluorídrico (HF) em concentrações de $5 \%$ e $10 \%$ em diferentes tempos. O experimento foi realizado em 30 amostras divididas em dois grupos, as amostras após o condicionamento ácido, foram lavadas e secas. Na superfície das amostras foi aplicado o jato com óxido de alumínio para obter melhor rugosidade, logo após em todas as coroas foi utilizado o silano como agente de união, em seguida, os bráquetes metálicos foram cimentados com resina fotopolimerizável. As amostras foram submetidas a prova de resistência de Newton em uma máquina de teste universal. Os resultados revelaram maior resistência com ataque ácido em concentração de $10 \%$, mas sem diferença estatisticamente relevante entre as amostras.

PALAVRAS-CHAVE: Ácido fluorídrico. Porcelana dentária. Cimentos de resina.

\section{ABSTRACT}

The objective of this in vitro research is to know the best method of conditioning on feldspathic porcelain surfaces, which allows better adhesion to the brackets using hydrofluoric acid (HF) at 5\% and 10\% considering the times of use. It was experimented in 30 samples divided into two groups, the same ones that after conditioning with HF, were washed with water jet and dried with the compressor. The samples were sand-blasted with aluminum oxide to achieve better surface roughness, subsequently silane was established in all the crowns as a bonding agent, and then metal brackets were cemented using light-curing resin. The samples were subjected to Newton strength tests on a universal test machine. Results they revealed greater resistance with $10 \%$ of HF but no significant difference between the two options.

KEYWORDS: Hydrofluoric acid. Dental porcelain. Resin cements. 


\section{RESUMEN}

El objetivo de esta investigación in vitro, es conocer el mejor método de acondicionamiento en superficies de porcelana feldespática, que permitan mejor adhesión a los brackets utilizando ácido fluorhídrico (HF) al 5\% y 10\% considerando los tiempos de utilización. Se experimentó en 30 muestras divididas en dos grupos, las mismas que luego del acondicionamiento con HF, fueron lavadas con chorro de agua y secadas con aire. Se arenan las muestras con óxido de aluminio para lograr mejor rugosidad en la superficie, posteriormente se asentó silano en todas las coronas como agente de unión, luego se cementaron brackets metálicos utilizando resina y fueron fotopolimerizadas con la lámpara de luz alojena. Las muestras fueron sometidas a pruebas de resistencia de fuerza Newton en una máquina universal de ensayo. Resultados revelaron mayor resistencia con el 10\% de HF pero ninguna diferencia relevante entre las dos opciones.

PALABRAS CLAVE: Ácido fluorhídrico. Porcelana dental. Cementos de resina. 


\section{INTRODUÇÃO}

Atualmente, as consequências para a saúde devido às más formações odontológicas têm sido tratadas pelos pacientes e na idade adulta, a maioria possui próteses fixas e ao iniciar um tratamento ortodôntico, encontram dificuldades alterações como: descolamento dos bráquetes, fraturas ou perda total na base vítrea da porcelana feldspática. Essas alterações ocorrem devido aos procedimentos técnicos e produtos químicos utilizados na cimentação dos bráquetes ${ }^{1}$.

O método de cimentação de bráquetes com ácido fluorídrico, promove micro retenções, aumentando significativamente os valores de resistência ao cisalhamento, o que pode resultar em um aumento no benefício clínico ${ }^{2}$.

$\mathrm{O}$ condicionamento ácido em concentrações de $5 \% \mathrm{e}$ $10 \%$ durante 120 segundos, modifica a matriz vítrea em canais que permitem a passagem do silano sem afetar ou causar fraturas, garantindo a conservação ou integridade da prótese fixa no momento da remoção dos suportes ${ }^{3}$.

A crescente demanda por tratamento estético e ortodôntico em pacientes adultos é mais frequente, os ortodontistas atualmente enfrentam o problema da colagem de bráquetes ortodônticos a dentes que possuem diferentes tipos de restaurações, incluindo prótese fixas de porcelana e laminados cerâmicos. No entanto, tem sido frequentemente relatado que a resistência das resinas compostas às restaurações cerâmicas é inadequada.

Por esta razão, o objetivo desta pesquisa é determinar qual é a melhor opção de condicionamento ácido na porcelana feldspática utilizando o ácido fluorídrico de $5 \% \mathrm{e}$ $10 \%$, considerando o tempo de exposição, seguindo os procedimentos de abrasão com jato de óxido de alumínio, silanização, colagem dos bráquetes e fotopolimerização. $\mathrm{O}$ teste de cisalhamento avaliou o nível de resistência dos bráquetes às próteses de porcelana fixa. Processos complementares também são essenciais, pois nos ajudarão a obter melhores resultados ao condicionar a cerâmica.

$\mathrm{O}$ resultado deste estudo permitirá estabelecer um protocolo adequado na prática clínica, de forma a garantir ao paciente e ao clínico um menor risco, tempo e excelente tratamento ortodôntico, sem danificar as próteses fixas.

\section{REVISÃO DE LITERATURA}

O objetivo da revisão da literatura é visualizar os critérios, desenvolvimento e resultados das investigações sobre a adesão de bráquetes metálicos em porcelana feldspática, condicionadas com ácido fluorídrico e considerando o tempo de registro ácido na superfície da cerâmica por processos químicos e uso de equipamentos. Esta pesquisa permitirá estabelecer um critério assertivo que aborda a realidade na prática ortodôntica clínica em pacientes que tenham próteses dentárias fixas e seja capaz de determinar o protocolo que garante a melhor opção para o paciente.

\section{Características da Cerâmica Feldspato}

A cerâmica feldspática é a porcelana mais utilizada para uso odontológico, contendo exclusivamente os três elementos básicos da cerâmica: feldspato, quartzo e caulim. Ao longo do tempo, a composição das porcelanas foi modificada até chegar as atuais cerâmicas. O feldspato, quando dividido em vidro, é responsável pela transluscência da porcelana, o quartzo é a fase cristalina, a caulim confere plasticidade e facilita o manuseio da cerâmica quando ainda não está cozida. Por serem basicamente de vidro, possuem excelentes propriedades ópticas que nos permitem alcançar bons resultados estéticos; são ao mesmo tempo frágeis, portanto não podem ser usados em próteses fixas se não estiverem apoiadas sobre uma estrutura. Por essa razão, essas porcelanas são usadas principalmente para o revestimento de estruturas metálicas ou cerâmicas. As atuais porcelanas feldspática de alta resistência têm uma composição muito semelhante à descrita acima. Possuem um alto conteúdo de feldspatos, mas são caracterizados pela incorporação à massa cerâmica de certos elementos que aumentam sua resistência mecânica (100-300 Mpa). Entre eles estão: Optec-HSP (Jeneric), Fortress (Myron Int), Finesse AllCeramic (Dentsply) e IPS Empress I (Ivoclar), 2011, (Ceramco).) Elas devem sua resistência a uma dispersão de microcristais leucita, distribuídos uniformemente na matriz vítrea. Essa diferença de volume entre os cristais e a massa amorfa gera tensões residuais que são responsáveis por combater a propagação de rachaduras. IPS Empress II (Ivoclar). São considerados materiais cerâmicos aqueles produtos de natureza inorgânica, constituídos por elementos não metálicos, obtidos pela ação do calor e cuja estrutura final é parcial ou totalmente cristalina. É importante notar que a fase vítrea é responsável pela estética da porcelana e enquanto a fase cristalina é responsável pela resistência. Portanto, a microestrutura da cerâmica tem grande importância clínica, uma vez que o comportamento estético e mecânico de um sistema depende diretamente de sua composição. Quimicamente, as porcelanas dentárias podem ser agrupadas em três grandes famílias: feldspato, alumina e zircônia ${ }^{4}$.

A Figura 1 permite conhecer o composto genérico e a porcentagem de participação, bem como a funcionalidade que cada um dos componentes da porcelana possui. 


\begin{tabular}{|c|c|c|c|c|}
\hline \multicolumn{5}{|c|}{$\begin{array}{l}\text { COMPOSTOS GENÉRICOS DE PORCELANAS DENTÁRIAS DA CONCEPÇÃO CLÁSSICA OU } \\
\text { CONVENCIONAL, PROPORÇÃO NAS FUNÇŐES DE MASSA TOTAL E PRÓ-NUUCLEO DE CADA UM } \\
\text { DOS COMPOSTOS }\end{array}$} \\
\hline Composto & $\begin{array}{l}\text { Proporção } \\
\text { aproximada no } \\
\text { total da massa } \\
\text { cerâmica }\end{array}$ & \multicolumn{3}{|c|}{ Função } \\
\hline Feldspato & $75-85 \%$ & $\begin{array}{l}\text { Feldspato de } \\
\text { potássio }\end{array}$ & \multicolumn{2}{|c|}{$\begin{array}{l}\text { Aumenta a viscosidade } \\
\text { Controle de manuseio } \\
\text { Melhora transluscência derrete caulim e } \\
\text { quartzo }\end{array}$} \\
\hline & & $\begin{array}{l}\text { Feldspato de } \\
\text { sódio }\end{array}$ & \multicolumn{2}{|c|}{$\begin{array}{l}\text { Diminui a temperatura de fusão } \\
\text { Manipulação minúscula }\end{array}$} \\
\hline Quartzo(silica) & $12-22 \%$ & \multicolumn{3}{|c|}{ Formar a fase cristalina } \\
\hline Caulim & $3-5 \%$ & \multicolumn{3}{|c|}{ Manuseio para massa/opacidade } \\
\hline \multirow[b]{2}{*}{ Fluxos } & \multirow[b]{2}{*}{ Variável } & \multicolumn{2}{|l|}{ Bórax } & \multirow{2}{*}{$\begin{array}{l}\text { Diminuir o ponto de } \\
\text { fusão }\end{array}$} \\
\hline & & \multicolumn{2}{|l|}{$\begin{array}{l}\text { Carbonatos } \\
\text { Óxido de zinco }\end{array}$} & \\
\hline \multirow{8}{*}{$\begin{array}{l}\text { Pigmentos/ } \\
\text { Corantes }\end{array}$} & \multirow{8}{*}{ Variável<1\% } & \multicolumn{3}{|c|}{ De cor e textura } \\
\hline & & \multirow{7}{*}{$\begin{array}{l}\text { Óxidos de } \\
\text { metal }\end{array}$} & Ferro & Marrom \\
\hline & & & Cobre & Verde \\
\hline & & & Cromo & Verde \\
\hline & & & Manganês & Azul claro \\
\hline & & & Cobalto & Azul escuro \\
\hline & & & Titânio & Marrom amarelo \\
\hline & & & Niquel & Marrom \\
\hline Maquiagem & Variável & \multicolumn{3}{|c|}{ Caracterização e individualização } \\
\hline Opacificadores & Variável & \multicolumn{3}{|c|}{ Mascarando áreas subjacentes } \\
\hline
\end{tabular}

Figura 1 - Composição da cerâmica feldspática e funcionalidade ${ }^{4}$.

\section{Efeitos do Ácido na Cerâmica}

Um dos problemas mais comuns da ortodontia é o descolamento de bráquetes quando foram colados em superfícies de porcelana, que tem sido aplicado diferentes métodos de condicionamento cerâmico ${ }^{1}$.

O ácido fluorídrico (HF) é um composto químico altamente perigoso, corrosivo, com cheiro agudo e penetrante, composto de hidrogênio e flúor. Sendo um dos ácidos mais perigosos, deve ser manipulado com maior cautela. As soluções de HF são claras e incolores com uma densidade semelhante à água. A propriedade mais conhecida do HF é atacar o vidro. Também ataca esmaltes, cimento, borracha, couro, metais (especialmente ferro) e compostos orgânicos 5 .

Avaliou-se o efeito da concentração e o tempo de aplicação do ácido fluorídrico em porcentagens de $9.5 \% \mathrm{e}$ $4.6 \%$ no tempo de 20, 40, 60 segundos na superfície do dissilicato de lítio, nos processos de e adesão a um substrato resinoso. Os autores concluem que, após os resultados estatísticos, as concentrações de ácido fluorídrico em 4.6\%, apresentaram melhores médias de adesão em comparação com a concentração de $9.6 \%$. O grupo com concentração de $4.6 \%$ em 20 segundos apresentou os melhores resultados ${ }^{6}$.

As composições cerâmicas são combinações de materiais metálicos e não metálicos, podem ser consideradas que já estão corroídas. Portanto, as cerâmicas são excessivamente resistentes à corrosão na maioria dos ambientes; sabendo que a corrosão dos materiais cerâmicos geralmente acontece como uma simples dissolução química? .

Devido à sua superfície inerte, a porcelana não adere a outros materiais, o que torna necessário alterar as características de sua superfície, para criar uma forte união entre sua superfície e os aparelhos, e assim ser capaz de resistir às forças necessárias utilizadas em tratamentos ortodônticos. Um dos agentes químicos comumente utilizados para produzir retenção micromecânica é o HF. Esta técnica de ataque ácido produz na porcelana não alumina uma penetração uniforme em profundidade que fornece retenção micromecânica para união sem alterar sua superfície ${ }^{8}$.

Considerando as características dos ácidos ${ }^{8}$, o ácido fosfórico é uma substância na forma de gel, viscoso que é responsável por fornecer uma superfície porosa no esmalte dentário, o ácido hidrofluorídrico é uma substância usada para a preparação de superfícies cerâmicas contra adesivos. Quando observados no microscópio eletrônico de varredura MEV podemos determinar qual das duas substâncias, 9,6 \% de ácido fluorídrico e 35\% ácido fosfórico tem maior grau de rugosidade, o parâmetro de rugosidade de cada ácido, será observado através de uma única imagem de cada grupo (Figuras 2, 3, 4 e 5).

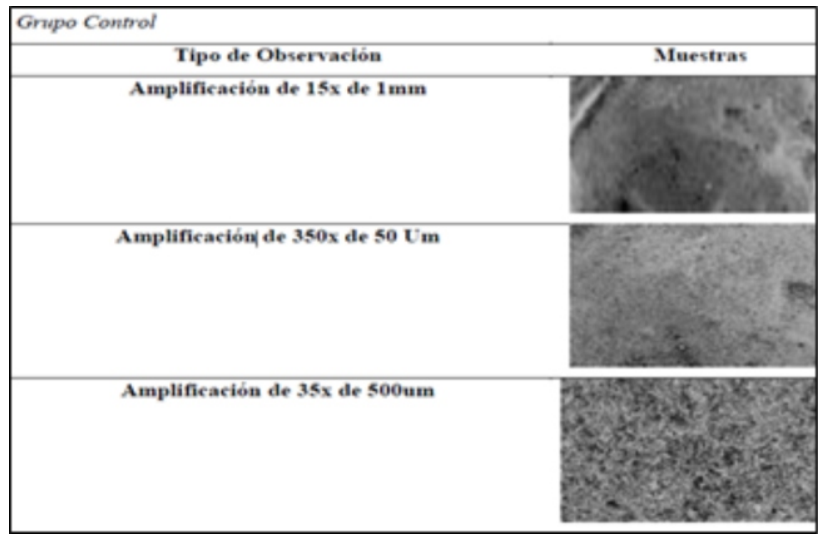

Figura 2 - Grupo controle, amostras sem colocação de substâncias ${ }^{8}$.

\begin{tabular}{|c|c|}
\hline Gripo 1 & \\
\hline Tipo de Observación & Muestras \\
\hline Amplificación de $15 \mathrm{x}$ de $1 \mathrm{~mm}$ & \\
\hline Amplificación de 350x de $50 \mathrm{Um}$ & \\
& \\
\hline Amplificación de 35x de 500um & \\
\hline
\end{tabular}

Figura 3 - Amostras com $\mathrm{HF}$ a 9,6\% durante 90 segundos $^{8}$. 


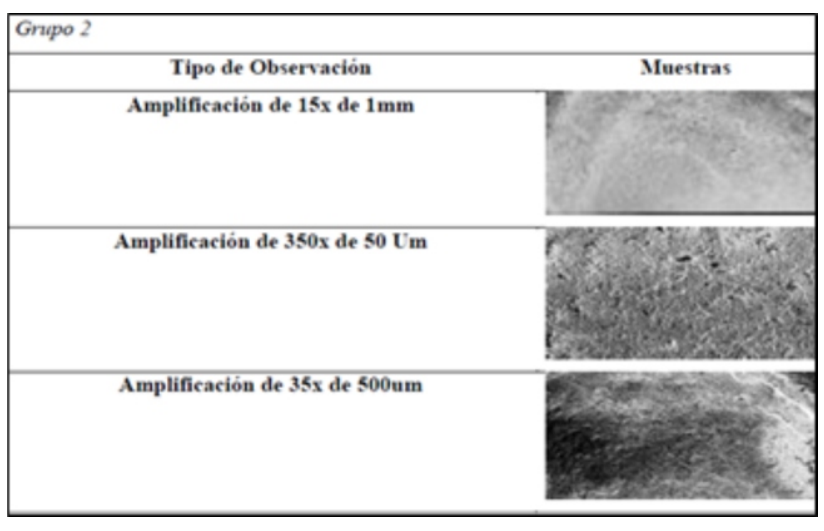

Figura 4 - Amostras com HF a 9,6\% durante 30 segundos $^{8}$.

\begin{tabular}{|c|c|}
\hline \multicolumn{2}{|l|}{ Grapo 3} \\
\hline Tipo de Observación & Muestras \\
\hline Amplificación de $15 x$ de $1 \mathrm{~mm}$ & \\
\hline Amplificación de $350 \mathrm{x}$ de $50 \mathrm{Cm}$ & \\
\hline Amplificación de $35 x$ de $500 u m$ & \\
\hline
\end{tabular}

Figura 5 - Amostras com HF a 9,6\% durante 60 segundos $^{8}$.

O ácido fluorídrico $9.6 \%$ é eficaz para fazer o ataque ácido na cerâmica, desde que a superfície seja tratada usando o tempo indicado pelo fabricante, um tempo excessivo de condicionamento com ácido fluorídrico resulta na dissolução completa da matriz vítrea, estimulando o deslocamento, diminuindo as retenções micromecânicas e fragilizando a restauração protética, ao contrário, o ácido ortofosfórico fosfórico em $35 \%$ apresenta um parâmetro de alta rugosidade utilizado nos três tipos tempo empregados ${ }^{8}$.

Evidências em amostras tratadas com ácido fluorídrico durante 1 minuto apresentam valores de resistência estatisticamente superiores à amostra de controle. Um tempo excessivo de condicionamento com ácido fluorídrico promove a dissolução completa da matriz vítrea ao redor dos cristais, causando o deslocamento dos cristais, diminuindo retenções micromecânicas e fragilizando a restauração protética. Para este tipo de porcelana, e de acordo com os resultados obtidos, o tempo de condicionamento com ácido fluorídrico por 2 minutos pode ser excessivo, uma vez que, embora melhore os valores em relação às amostras não condicionadas, não apresenta diferenças estatisticamente significativas. Os resultados encontrados não podem ser extrapolados para outros sistemas cerâmicos, que possuem composição e percentual de fase vítrea e cristalina diferente 9 .

Outros estudos confirmam o efeito da concentração e do tempo de aplicação do ácido fluorídrico sobre os valores de adesão a um material resinoso ${ }^{10-12}$. Onde, na maior concentração e tempo de aplicação, há uma tendência a diminuir os valores de adesão nesse tipo de material. Em estudo, mostrou-se que o ácido fluorídrico $4.6 \%$ condicionado durante 20 segundos, obtém melhores resultados em relação à força adesiva do dissilicato de lítio, seguido pela mesma concentração, mas com um tempo de aplicação de 40 e 60 segundos. Houve também diminuição nos valores de adesão, quando a concentração e o tempo de aplicação do agente de condicionamento foram aumentados ${ }^{6}$.

A pesquisa avaliou a força de tração dos bráquetes metálicos em amostras de discos de feldspato e óxido zircônio, considerando areação do jato com óxido de alumínio aplicado a superfície por 4 segundos a uma pressão de 2.5 bar, deve-se ressaltar que para o tratamento das superfícies foi utilizado o ácido fluorídrico $4 \%$ nos protocolos de condicionamento. A partir dos resultados obtidos neste estudo, o autor concluiu que a união dos acessórios ortodônticos metálicos, com aplicação de jato de óxido de alumínio na superfície da porcelana feldspática e zircônia, com condicionador de porcelana, Reliance Assure, Reliance Asure plus e Zprime plus resultou em intensidades de união maiores do que a retenção mecânica entre $\mathrm{o}$ adesivo e a base dos bráquetes ${ }^{13}$.

No estudo realizado com dois tipos de Cerâmica, Feldspática (Vita Mark II) e dissilicato de lítio (e.max) foram utilizados seis blocos, No.14, de cada cerâmica. Cada bloco foi seccionado em para cinco peças. Duas concentrações de ácido HF, a 5\% (a) e 10\% (b), foram utilizadas para cada cerâmica. Três tempos de condicionamento foram avaliados neste estudo: 20, 60 e 120 segundos. Portanto, tivemos seis subgrupos para cada cerâmica (30 peças): Ma 20, Ma 60, Ma 120, Mb 20, Mb 60, Mb 120 (subgrupos Vita Mark II) e Ea 20, Ea 60, Ea 120, Eb 20, Eb 60, Eb 120 (subgrupos e.max). Após o condicionamento e de acordo com o tempo de condicionamento, eles foram enxaguados com ar de spray e água por 30 segundos. Eles foram então ultrasonicamente limpos em água destilada por cinco minutos. Para a remoção de qualquer contaminação da superfície cerâmica, o gel de ácido fosfórico foi usado por cinco segundos nas peças e depois lavado e seco com ar e colocado em $99 \%$ de álcool. O método de ataque ácido foi realizado com base em seu subgrupo. Uma camada de mistura igual de agente de união e de silano CLEARFIL foi aplicada a todas as peças cerâmicas e secas com ar por 60 segundos. Em seguida, uma camada de resina CLEARFIL SE foi aplicada na cerâmica. Depois disso, uma quantidade igual de pasta Panavia A e B foram misturadas por mais de 20 segundos e aplicadas a cerâmicas preparadas. A polimerização foi realizada por 20 segundos com luz VALO LED (Ultradent) 
com intensidade de $1.000 \mathrm{~mW} / \mathrm{cm}^{2}$ aplicado nas interfaces de cimento de cada lado. Para o teste de resistência, as peças foram seccionadas perpendicularmente à área de interface de junção usando um disco diamantado refrigerado a água em uma máquina de secção, para obter duas partes paralelas com uma área de junção de aproximadamente $1 \mathrm{~mm} 2$. Duas partes foram obtidas de cada peça. Portanto, 10 partes em cada grupo experimental foram testadas (60 partes totais). A área transversal de cada feixe foi medida usando um calibre digital. A resistência de união ao cisalhamento foi avaliada com a máquina de teste universal (Zwick GmbH \& Co., Ulm, Alemanha) a uma velocidade de $0.5 \mathrm{~mm} / \mathrm{min}$ até a quebra. As pressões em Mpa foram calculadas. Os resultados mostraram que, nos grupos e.max e Vita Mark II, a resistência ao cisalhamento não foi significativamente diferente quando diferentes tempos de condicionamento e concentrações de ácido HF foram utilizados, mas a resistência foi maior nos grupos Ea 60 e Mb 20. A micro retenção é importante para estabelecer a ligação da resina com a restauração. No processo de cimentação de uma restauração cerâmica, é importante ter um condicionamento adequado da superfície ${ }^{14}$.

\section{Ácido Fluorídrico}

O ácido fluorídrico a 5\% e 10\% (Maquira Indústria de Produtos Odontológicos Ltda., Maringá, Brasil), é um ácido em gel, é o condicionador mais eficiente e usado para acondicionar as superfícies de porcelana, permitindo maior retenção de materiais resinosos em restaurações com porcelanato feldspática, vidro cerâmico e fixação de bráquetes ortodônticos. Sua viscosidade adequada e a presença do corante permitem uma aplicação segura, sem perigo de vazamento e melhor visualização da região que será condicionada. Sua composição apresenta: ácido fluorídrico de $5 \%$ ou $10 \%$, espessante, corante e água purificada. O modo de uso recomendado pelo fabricante de porcelana feldspática é de 1 a 2 minutos, depois o uso de água em abundância para a remoção do produto.

\section{Óxido de Alumínio}

Ao utilizar micro abrasão com jato de óxido de alumínio na superfície de porcelana promove alterações na cobertura, mas aumenta a rugosidade localizada na área destinada a cimentar os bráquetes, promovendo uma força de adesão de $2.8 \mathrm{Mpa}^{2}$.

\section{Características do Silano}

Silano (Maquira Indústria de Produtos Odontológicos Ltda., Maringá, Brasil) são moléculas bifuncionais que agem como promotoras de adesão. É um agente de união que seu propósito é aumentar a adesão química entre materiais orgânicos, adesivos contendo monômeros metacrílicos e inorgânicos, como cerômeros, resina completa, pinos de fibra de vidro e cerâmicas contendo fase vítrea. O uso do silano como agente de união é essencial, pois a resistência da resina é determinada pela resistência adesiva entre o preenchimento e a matriz. O fabricante recomenda: para a cimentação indireta com cimentos resinosos, a superfície é preparada de acordo com a técnica recomendada pelo agente de cimentação, em seguida, realizar o condicionamento ácido usando o condicionador de porcelana na superfície para o tempo recomendado pelo fabricante, lavar e secar cuidadosamente. Finalmente o silano é aplicado com a ajuda de um pincel, espere 1 minuto e aplique uma nova camada, secar lentamente com ar, cimentar com a resina de acordo com as instruções do produto.

O silano contém moléculas de silano e acrílicas, a primeira reage formando uma ligação química com a sílica (composto inorgânico de porcelana) e as moléculas acrílicas aderem à parte orgânica do adesivo (resina). Por essa razão, quando o teor de sílica é baixo na porcelana, o efeito sobre a força de adesão do silano é baixa ${ }^{15}$.

\section{Resistência ao Cisalhamento}

Um estudo comparou diferentes métodos de tratamento na superfície da porcelana sobre a resistência ao cisalhamento (SBS) e o modo de fratura dos bráquetes ortodônticos. Setenta amostras de disco de porcelana feldspática montadas em blocos de resina foram divididas em sete grupos (n-10) de acordo com o tipo de tratamento da superfície: I - Broca diamantada; II Ácido ortofosfórico (OPA); III - ácido fluorídrico (HF); IV jateamento com óxido de alumínio (SB); V - SB + HF; VI neodímio: laser ítrio-alumínio-granada (Nd: YAG); VII - erbio: ítrio-alumínio-granada (Er: YAG). Os bráquetes foram fixados nas superfícies tratadas de porcelana, com um agente de união silano e resina adesiva e foram submetidos aos testes de SBS. As amostras foram avaliadas de acordo com o índice adesivo restante (IAR), e os modos de falha foram avaliados quantitativamente sob um microscópio eletrônico (Figura 6) e morfologicamente sob um microscópio eletrônico de varredura (MEV). A análise estatística foi realizada utilizando-se análise de variância a um critério e o teste de Tukey ${ }^{16}$.

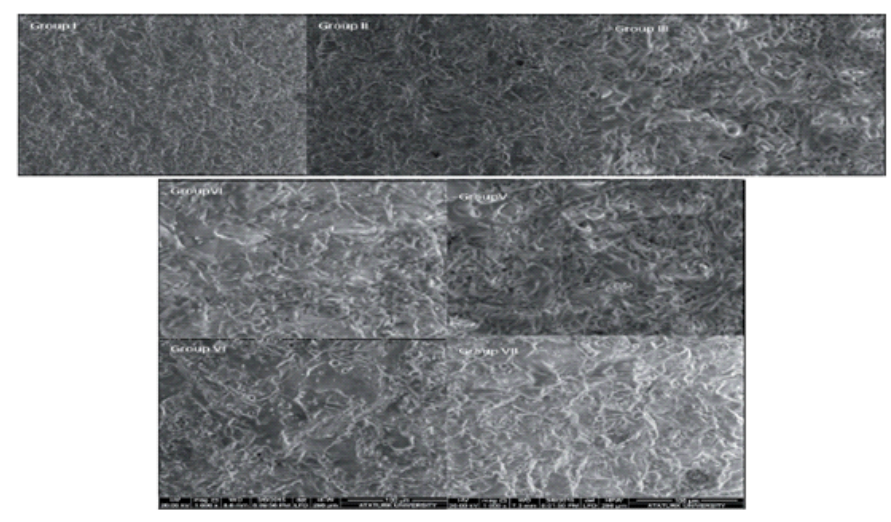

Figura 6 - Fotografias de microscópio eletrônico de varredura ${ }^{16}$. 
Os resultados indicam que a broca diamantada sozinha, é incapaz de condicionar superfícies de porcelana para a união de bráquetes. Além disso, o ataque químico SB e HF usado em combinação resulta em resistência significativamente maior ao cisalhamento quando comparado ao HF ou SB. O laser (Nd: YAG) ou (Er: YAG) é mais eficaz com menos tempo em relação à $\mathrm{SB}$ ou ao $\mathrm{HF}$ para o tratamento de porcelana feldspática ${ }^{16}$.

Atualmente existem vários condicionamentos de précimentação de uma cerâmica feldspática que são feitas na superfície interna para modificar sua morfologia e criar retenção micromecânica e química para obter maior adesão dentária. Outro estudo comparou a aparência superficial e a força adesiva, em uma cerâmica feldspática Ex-3 condicionada com diferentes concentrações e tempos de exposição ao ácido fluorídrico. Foram fabricadas 60 amostras cerâmicas, divididos aleatoriamente em três grupos $(n=20)$; e condicionamento da superfície interna com micro abrasão e diferentes concentrações e tempos de exposição ao ácido fluorídrico. As superfícies foram medidas em um rugosímetro, observadas e analisadas no microscópio eletrônico de varredura $(500$ X, 1500 X) antes e depois do condicionamento. Este estudo utilizou uma estatística descritiva básica composta por valores médios, de desvio padrão, mínimo e máximo, e intervalos de confiança de $95 \%$, um teste T pareado, bem como ANOVA e uma análise de Scheffé para comparar diferentes grupos usando o programa Stat View 4.5. As diferenças estatisticamente significativas nos três grupos cerâmicos condicionados foram encontradas no estudo da força adesiva, com um valor de $(\mathrm{p}<0001)$ onde a força do grupo condicionado com ácido a $9 \%$ por 1 minuto com uma adesão de 9,03Mpa, mostrou maior força de adesão, seguido de ácido a $10 \%$ por 2 minutos com $8.08 \mathrm{Mpa}$, e finalmente com menor adesão com ácido $5 \%$ por 2 minutos com 5.06 Mpa. Diferentes concentrações e tempos de ácido fluorídrico modificam significativamente a aparência superficial e a força adesiva da cerâmica feldspática ${ }^{17}$. Os resultados deste estudo são mostrados nas Figuras 7 e 8.

\begin{tabular}{|c|c|c|c|c|}
\hline Adhesión & Media & \multicolumn{2}{|c|}{$\begin{array}{l}\text { Desviaciòn } \\
\text { estándar }\end{array}$} & $\begin{array}{l}\text { Intervalos } \\
\text { de confianea } \\
\text {. }\end{array}$ \\
\hline IPS Coramic (Graboda) & 4.249 & .380 & 4.000 .4 .990 & 4.0724 .427 \\
\hline Porcelain Etch (Grabada) & 9.004 & .049 & $8.960-9.120$ & 9.0114 .057 \\
\hline $\begin{array}{c}\text { Finesse all Ceramic } \\
\mid \text { Grabada } \mid\end{array}$ & 6.005 & .094 & $5.950-6.080$ & $5.909-6.021$ \\
\hline
\end{tabular}

Figura 7 - Estatística descritiva da resistência ao cisalhamento ${ }^{17}$.

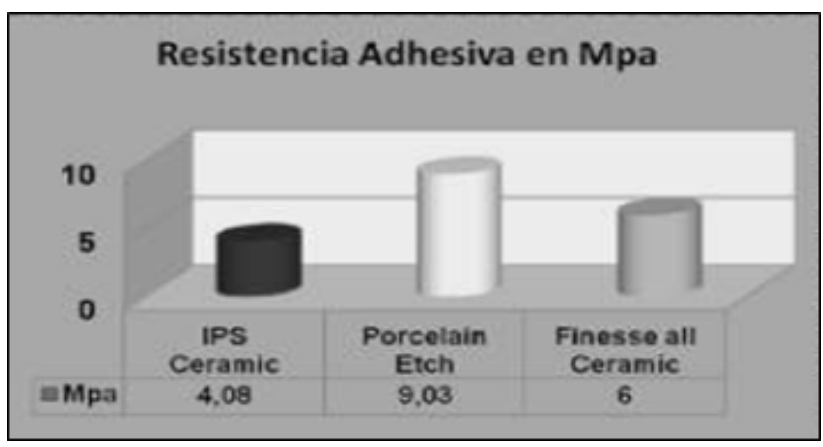

Figura 8 - Comparação da resistência ao cisalhamento expressa em $\mathrm{Mpa}^{17}$.

\section{Resistência ao Cisalhamento dos Bráquetes}

Os resultados do estudo indicam que o tempo de condicionamento é um fator decisivo para a força de união dos bráquetes à cerâmica. Embora os dentistas devam seguir as recomendações do fabricante para procedimentos de união, 60 segundos é o tempo de condicionamento para a união da cerâmica feldspática, que poderia ser recomendado. No entanto, deve-se ter cuidado ao selecionar o tempo de condicionamento de cada material, pois estudos prévios têm mostrado efeitos negativos de um excesso do ataque químico na cerâmica, como a difícil penetração do agente de união nas irregularidades e possível falha de coesão do material. Por outro lado, embora a fonte de luz seja apresentada sem influência significativa, o uso de unidades de alta intensidade ainda é recomendado para garantir a eficácia da polimerização da resina. Por fim, os profissionais devem estar atentos aos efeitos nocivos do ácido fluorídrico e do cuidado durante a aplicação clínica ${ }^{18}$.

A utilização de diferentes combinações de bráquetes, adesivos e fonte de luz na força da adesão à tração à porcelana aos padrões de falha da união foram estudados por testes de tração, utilizando-se: um bráquete de cerâmica comparado a um bráquete metálico, dois materiais de resina ortodônticos; de bisfenol tipo A e metacrilato de uretano (UDMA), e quatro unidades de luz com a mesma faixa de espectro de emissão, mas de diferentes intensidades de luz LED e a alógena. As 160 amostras foram divididas em grupos iguais de 16 unidades, que foram condicionadas com ácido fluorídrico a 9\% antes da aplicação de silano, posteriormente a fotopolimerização por 40 segundos. Após o armazenamento em água a $37^{\circ} \mathrm{C}$ por 24 horas, estes foram submetidos à força de tração até a falha. $\mathrm{O}$ autor conclui que a força de união nos dois grupos foi suficiente para suportar o tratamento ortodôntico, não houve diferença estatística entre os adesivos, a interação da luz, foi significativamente maior com bráquetes cerâmicos com luz LED. Não foram observadas diferenças significativas nos bráquetes metálicos, não foram observadas fraturas com bráquetes metálicos, mas ocorreram fraturas em 35\% dos bráquetes 
cerâmicos e o risco de fratura foi maior quando os bráquetes foram utilizados com resina UDMA e menor com luz LED de alta intensidade. Ressalta-se que o ácido fluorídrico foi utilizado para este estudo e não teve relevância para os métodos de pesquisa do autor ${ }^{3}$.

\section{Estudos Realizados com Diferentes Concentrações}

Sugere-se que a adesão ideal a uma superfície de porcelana deve permitir o tratamento da ortodontia sem falha na adesão e sem danificar sua integridade após a remoção dos bráquetes. Considera-se que uma força de união adequada na adesão dos bráquetes ao esmalte deve ser de 6 a $8 \mathrm{Mpa}$. Dentro da revisão bibliográfica, os diferentes autores concluem que a melhor opção para condicionamento de suporte é o uso de ácido fluorídrico a $9.6 \%$ e o silano, em comparação com o uso de ácido fosfórico de $37 \%$ e o Primer de porcelana ${ }^{8}$.

Determinaram qual o ácido produz a maior rugosidade na superfície da cerâmica feldspática, utilizando dois tipos de agente de condicionamento. Os materiais e métodos utilizados foram 30 discos de porcelana feldspato IPS Clasic (Ivoclear Vivadent) com $10 \mathrm{~mm}$ de diâmetro e $2 \mathrm{~mm}$ de espessura, que foram separados em dois grupos, dependendo do tipo de tratamento que receberiam: a) condicionamento de ácido fluorídrico de $9 \%$ por 60 segundos e b) condicionamento de ácido ortofosfórico de $37 \%$ por 120 segundos. As amostras foram então levadas a um perfilômetro para avaliar quantitativamente de rugosidade produzida na superfície. Os resultados do condicionamento em cerâmicas feldspática com HF em $9 \%$ foram maiores em comparação com o ácido ortofosfórico $37 \%$, sendo está a conclusão do autor ${ }^{19}$.

Um artigo, que mostra diferentes métodos utilizados na ortodontia para o condicionamento da porcelana antes da adesão dos bráquetes, esses métodos podem ser: mecânico, químico e uma mistura dos dois anteriores. O primeiro corresponde à abrasão com pedras verdes, brocas diamantadas de granulação grossa, micro abrasão com jato de óxido de alumínio ou sílica, ou discos diamantados, que aumentam a rugosidade nas superfícies de porcelana aumentando a força de adesão com a desvantagem de fratura utilizando a micro abrasão com jato de óxido de alumínio, afeta a superfície externa mas aumenta a rugosidade na área destinada a cimentar os bráquetes, relatando uma força de adesão de $2.8 \mathrm{Mpa}$. Os métodos químicos para a preparação da superfície de porcelana incluem diferentes substâncias, sendo a mais estudada a (HF) em diferentes concentrações. Outras substâncias utilizadas são flúor de fosfato acidulado, e ácido fosfórico (H3PO4) a 37\%. Eles descobriram que a aplicação de FFA a 1.23\% em superfícies de porcelana previamente tratadas com pedras verdes para remover o glaze, resultou em uma força de adesão de $9.42 \mathrm{Mpa}$, semelhante àquelas relatadas com o uso de HF, sem correr os riscos acima. A função de $37 \%$ de ácido fosfórico é remover a partícula superficial da porcelana, removendo partículas de sílica, oxigênio e moléculas de hidrogênio para permitir sua ligação com moléculas de silano, para este caso foram encontradas forças de adesão aceitáveis, semelhantes às relatadas pelo ácido fluorídrico 9.6 Mpa e silano. O autor conclui que o melhor método é o uso de ácido fosfórico de $37 \%$, uma vez que com ácido fluorídrico, melhor adesão foi encontrada, mas devido à sua toxicidade não é um método de primeira escolha ${ }^{15}$.

$\mathrm{O}$ artigo de pesquisa para determinar a força de adesão de bráquetes metálicos cimentados em porcelana, com o uso de dois métodos de condicionamento. Os materiais e métodos foram feitos em 40 pré-molares humanos que foram submetidos a preparações para cimentação de coroas completas em metalocerâmica. Dois grupos foram feitos cada um de 20 dentes. Grupo 1. Condicionado com ácido fluorídrico (9.6\%) e aplicação de silano (HF + s). Grupo 2. Ácido fosfórico (37\%) e Primer para porcelana (AF + pp). Em seguida, os bráquetes metálicos foram cimentados, utilizando adesivo e Resina Transbond XT. As amostras foram testadas para resistência à força de corte com uma máquina de teste universal, Instron. Resultados: $\mathrm{O}$ aumento da força de adesão foi obtido no grupo $2(\mathrm{AF}+\mathrm{pp})$ com média de 9,4 Mpa, e para o grupo $1(\mathrm{HF}+\mathrm{s})$, um valor de 7.0 Mpa ( $\mathrm{p}=0.006)$. Conclusões: O melhor valor da força de adesão para o método de condicionamento de porcelana é o uso de ácido fosfórico à $37 \%$ e o primer para porcelana, com o ácido fluorídrico a $9,6 \%$ é considerado uma força de adesão aceitável, mas devido à sua toxicidade, danos permanentes à superfície cerâmica e proteção necessária durante a aplicação clínica, para o autor não é um método de primeira escolha para cimentar bráquetes em restaurações de porcelana ${ }^{20}$.

Outro estudo avaliou a resistência ao cisalhamento (SBS) de bráquetes metálicos e cerâmicos colados em duas diferentes coroas cerâmicas sem metal, IPS Imperatriz 2 e Alumina In-Ceram, para comparar a força de cisalhamento com o condicionamento ácida utilizando ácido fluorídrico de $9.6 \%$, e ácido fosfórico de $37 \%$ e jateamento abrasivo em noventa e seis coroas cerâmicas sem metal de um primeiro pré-molar esquerdo. Foram utilizados bráquetes metálicos e cerâmicos e uma resina adesiva e, em seguida, a luz de polimerização convencional foi utilizada. Uma máquina de teste universal Instron foi usada para determinar a SBS com uma velocidade de corte de $0,1 \mathrm{~mm} /$ minuto nos diferentes grupos. A SBS dos bráquetes metálicos descolados dos grupos 1,3 e 5 não foram significativamente diferentes daqueles dos grupos 2, 4 e 6 . Todos os bráquetes metálicos descolados revelaram um padrão semelhante de falha de adesão na interface da restauração adesiva. No entanto, os bráquetes cerâmicos apresentaram um padrão de falha adesiva significativamente diferente com falha predominante na interface do suporte adesivo. As fraturas das cerâmicas após a remoção dos bráquetes foram mais frequentemente encontradas nos grupos 1-4. Não foram observadas diferenças 
significativas na fratura cerâmica entre a Imperatriz IPS 2 e a In-Ceram. Os autores concluem que os bráquetes metálicos e cerâmicos condicionados com ácido fluorídrico nas coroas IPS Imperatriz 2 e In-Ceram tiveram resultados semelhantes em testes de resistência ao cisalhamento ${ }^{21}$.

\section{Estudos Semelhantes}

É essencial utilizar um exame sistemático para determinar quais materiais e técnica/protocolo têm a maior taxa de sucesso na colagem de bráquetes às superfícies de porcelana, um dos melhores protocolos descritos é o condicionamento com ácido fluorídrico ${ }^{22}$.

O objetivo do estudo foi avaliar o efeito do revestimento de sílica em uma cerâmica de alumina sinterizada em relação à sua resistência de união a um composto, utilizando um agente de cimentação de resina. Os discos de porcelana feldspática foram utilizados com diâmetro de $10 \mathrm{~mm}$ e espessura de $2 \mathrm{~mm}$ montados em blocos de resina acrílica, divididos em quatro grupos. Nos grupos 1 e 2, as superfícies de porcelana foram condicionadas com ácido fluorídrico (HF) em 9.6\% e nos grupos 3 e 4 com ácido $\mathrm{HF}$ de $5 \%$. Nos grupos 1 e 3 , bráquetes de incisivos centrais superiores foram colados com silano Pulpdent e nos grupos 2 e 4 com silano e Reliance. As forças de cisalhamento foram aplicadas às amostras usando uma máquina de teste universal Instron. $\mathrm{O}$ teste não paramétrico de Kruskal-Wallis foi usado para determinar diferenças significativas na força de união entre os quatro grupos e o teste de comparação múltipla de Dunn para comparar subgrupos. A resistência média de união e os desvios padrão dos grupos 1 a 4 foram $5.51 \pm 1.19,6.54 \pm$ $0.002,4.55 \pm 1.93$ e $6.39 \pm 0.45 \mathrm{Mpa}$, respectivamente. $\mathrm{O}$ autor concluiu que, embora o uso de $9.6 \%$ da HF tenha aumentado a resistência à união, não houve diferenças estatisticamente significativas com ácido de 5\% e 9.6\%. Portanto, um ataque ácido de $5 \%$ pode ser recomendado para aplicações intraorais, a fim de evitar irritação tecidual sem perda de resistência à união. As amostras do silano Reliance mostraram uma força de união estatisticamente significativa maior ou que as com silano Pulpdent $\mathrm{t}^{23}$.

Encontraram alterações morfológicas (poros e ranhuras regulares), no microscópio eletrônico de varredura em $1500 \mathrm{X}$ ao condicionar $9.5 \%$ de ácido fluorídrico em diferentes momentos, obtendo melhor adesão quando aplicado por 30 segundos. Isso pode ser feito pela distribuição de partículas finas e homogêneas de cerâmica Ex- $3^{24}$.

Encontram maior força de adesão quando na superfície foi produzida uma micro abrasão e condicionamento com ácido fluorídrico de $9 \%$ por 60 segundos em comparação com diferentes ácidos em tempos e concentrações ${ }^{25}$.

Estudos realizados para aprender sobre o efeito do condicionamento, tempo e fonte de luz sobre a força de adesão de bráquetes metálicos para cilindros de cerâmica feldspática, em que o HF é aplicado a 10\% por tempos de 20 e 60 segundos, seguido pela aplicação de silano, a colagem de bráquetes metálicos e fotopolimerização com diferentes tipos de luz alógena e submetidos ao teste de cisalhamento, em relação aos resultados, o autor conclui que o tempo de condicionamento é um fator decisivo para a resistência da união dos bráquetes aos cerâmicos. Embora os dentistas devam seguir as instruções do fabricante para procedimentos de colagem, o condicionamento da cerâmica feldspática é recomendada por 60 segundos. No entanto, deve-se ter cuidado ao selecionar o tempo de condicionamento de cada material, estudos prévios demonstraram efeitos negativos de um ataque químico excessivo na cerâmica, como a difícil penetração do agente de união nas irregularidades e possível falha de coesão do material. Por outro lado, a fonte de luz não teve relevância significativa para os dois processos ${ }^{18}$.

A resistência ao corte entre a resina composta e a cerâmica feldspática feita ao condicionamento de ácido fluorídrico (HF) em diferentes concentrações, foram feitas em 36 amostras de porcelana feldspática que foram incluídos em resina acrílica, dividido em três grupos (n 12): G1) sem condicionamento (controle); G2) condicionamento de $10 \%$ HF por 120 segundos; G3) condicionamento de 5\% HF por 120 segundos. Silano e adesivo foram então aplicados na superfície da porcelana; seguido pela inserção da resina composta com a ajuda de uma matriz metálica. Após sete dias de armazenamento na estufa, as amostras foram testadas para corte em uma máquina de teste universal. As médias de resistência foram G1 105, 3 N; G2 182, 5 N e G3 154, 51 N. Na análise dos dados quantitativos houve diferença estatisticamente significativa entre todos os grupos $(\mathrm{p}<0.05)$. A microscopia óptica revelou aproximadamente 58\% das falhas coesas para o G1, 75\% para G3 e $83 \%$ para G2. Concluiu-se que a adesão com o uso do HF a $10 \%$ foi superior a adesão obtida quando utilizado o $\mathrm{HF}$ a $5 \%$.

\section{MATERIAL E MÉTODOS}

Os materiais e equipamentos odontológicos selecionados para a execução desta pesquisa (Figuras 9 e10) proporcionam um resultado real, que permitirá decidir a melhor técnica de condicionamento do ácido na colagem de bráquetes em próteses fixas de porcelana feldspática. 


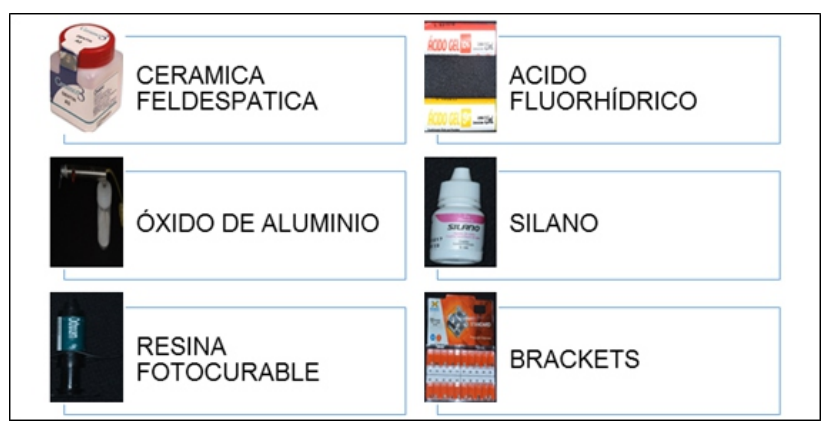

Figura 9-Materiais utilizados na pesquisa.

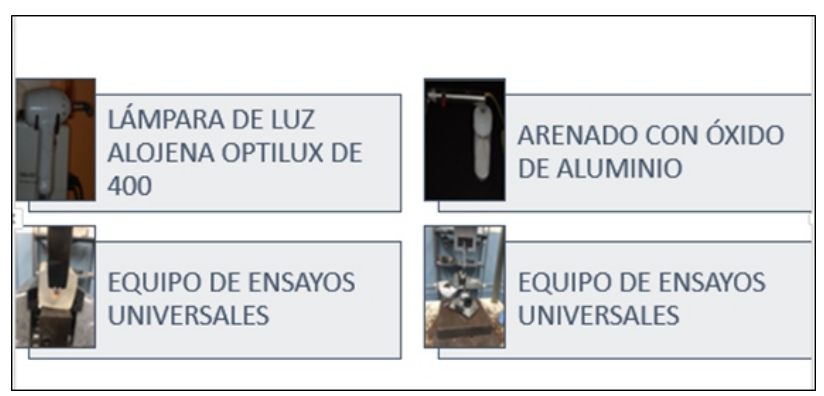

Figura 10 - Materiais utilizados na pesquisa.

As informações de artigos foram obtidas em páginas da web como: Pubmed, Scielo, Biblioteca Virtual em Saúde (BVS), Google Acadêmico. As indicações farmacológicas dos produtos, as diferentes técnicas, processos, tipos de materiais e utilização dos equipamentos recomendada pelos fabricantes, para a aplicação dos bráquetes em porcelana feldspática, foram utilizados como guia para a escolha do procedimento correto.

Antes da revisão de literatura, foi realizado o estudo experimental, para determinar o efeito que o ácido fluorídrico causa na porcelana feldspática e a resistência dos bráquetes metálicos colados nas próteses fixas considerando o percentual de ácido e independentemente do tempo de condicionamento, para o qual o seguinte protocolo foi determinado.

\section{Preparação da Amostra}

Foram de utilizadas 30 amostras de próteses fixas correspondentes a pré-molares superiores que possuem superfícies convexas e em porcelana feldspática (Ceramco 3 , Dentsply), estas foram fixadas em cubos de resina acrílica de $2 \times 2 \mathrm{~cm}$, com superfícies vestibulares expostas (Figura 11). Foram formados dois grupos experimentais de condicionamento da porcelana: Grupo A $(\mathrm{n}=15)$ coroas de porcelana feldspática condicionadas utilizando ácido fluorídrico de $5 \%$ e Grupo B ( $\mathrm{n}=15)$ coroas de porcelana feldspática utilizando ácido fluorídrico em gel a $10 \%$, por 120 segundos em ambas os grupos.

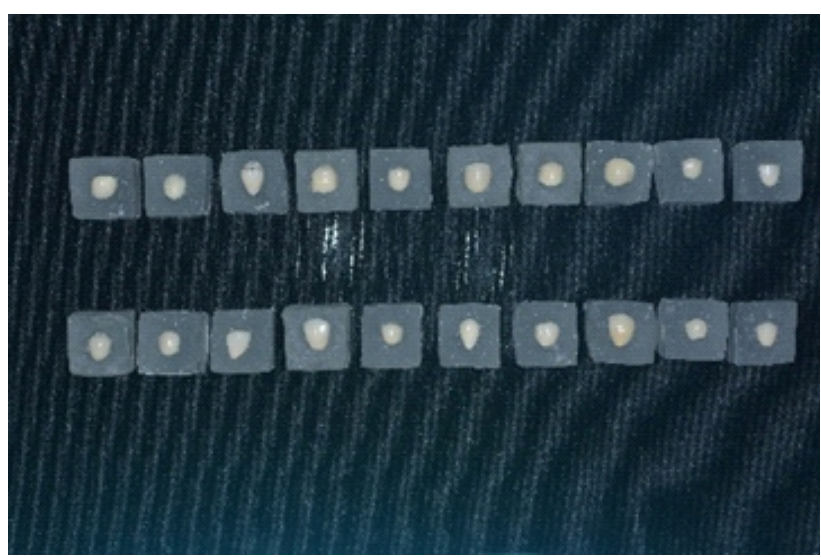

Figura 11 - Amostras de próteses fixas em cubos acrílicos.

\section{Condicionamento Ácido}

A colagem do bráquete em uma prótese fixa de porcelana feldspato foi realizada com o condicionamento por ácido fluorídrico (HF), que apresenta na sua composição flúor de hidrogênio, na qual tem a propriedade de corroer a matriz vítrea permitindo a retenção dos agentes de união entre a resina e o material. Neste estudo, o ácido fluorídrico em gel é utilizado nas concentrações de $5 \%$ e 10\%, (Maquira Indústria de Odontológicos S.A., Maringá, Brasil) pelo tempo de 2 minutos em cada amostra, as superfícies são lavadas por jato de água por 20 segundos e secas por mais 20 segundos com a seringa tríplice do equipamento odontológico (Figura 12).

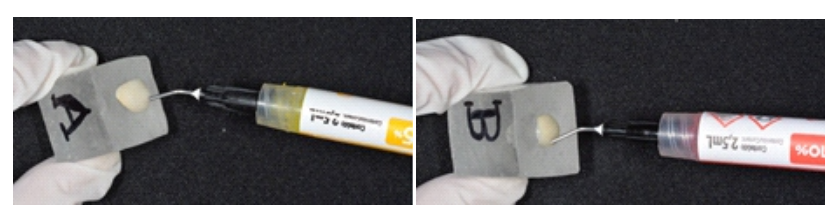

Figura 12 - Condicionamento das amostras com ácido fluorídrico.

\section{Jateamento}

Usando um jato com óxido de alumínio a 50 mícron, procedeu-se a jatear as próteses por 2 segundos a uma distância de 15 milímetros (Figura 13). Este procedimento altera a glaze na área localizada para a colagem do bráquete, e aumenta a rugosidade para a adesão. 


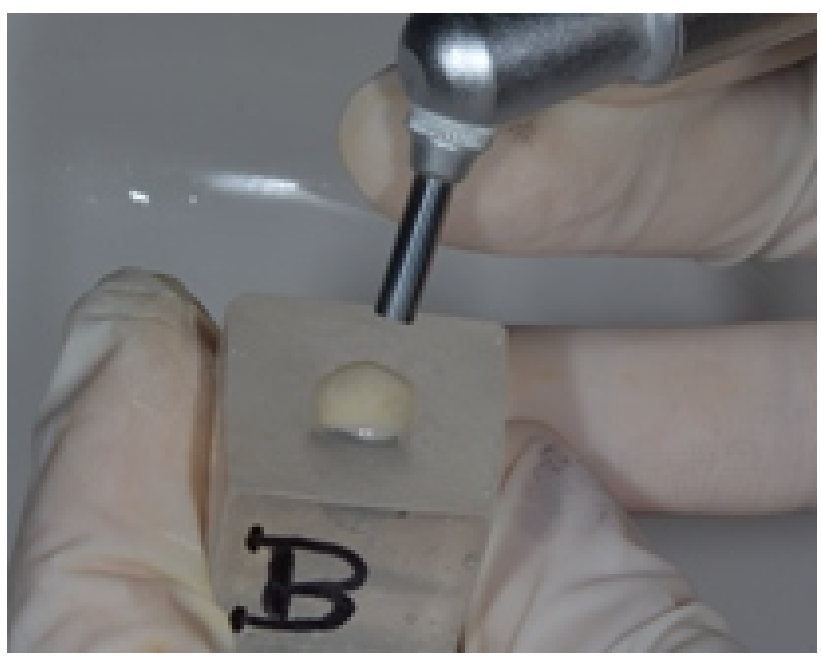

Figura 13 - Jateamento com óxido de alumínio.

\section{Método de Silanização ou Adesão}

Este procedimento atua como agente de união entre as coronas feldspática e os bráquetes, a silanização realiza-se por um período de 60 segundos (Figura 14).

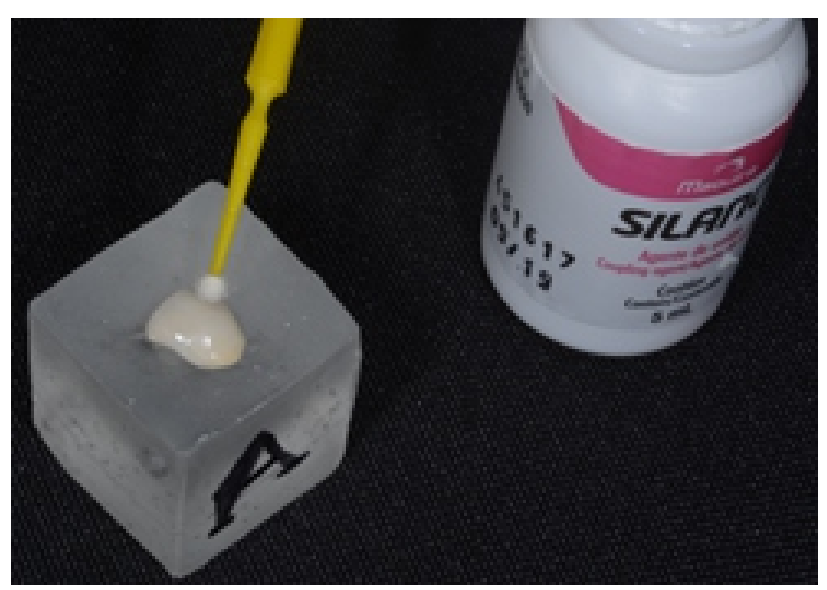

Figura 14 - Processo de silanização das amostras.

\section{Colagem dos Bráquetes}

É colocada a resina fotopolimerizável (Orthocem) na superfície vestibular da amostra e, em seguida, os bráquetes são posicionados no centro da coroa, removendo os excessos (Figura 15). Os bráquetes metálicos utilizados são da Prescrição Edgewise Standard para pré-molares (MORELLI, Slot 22, Dental Morelli Ltda., Sorocaba SP Brasil).

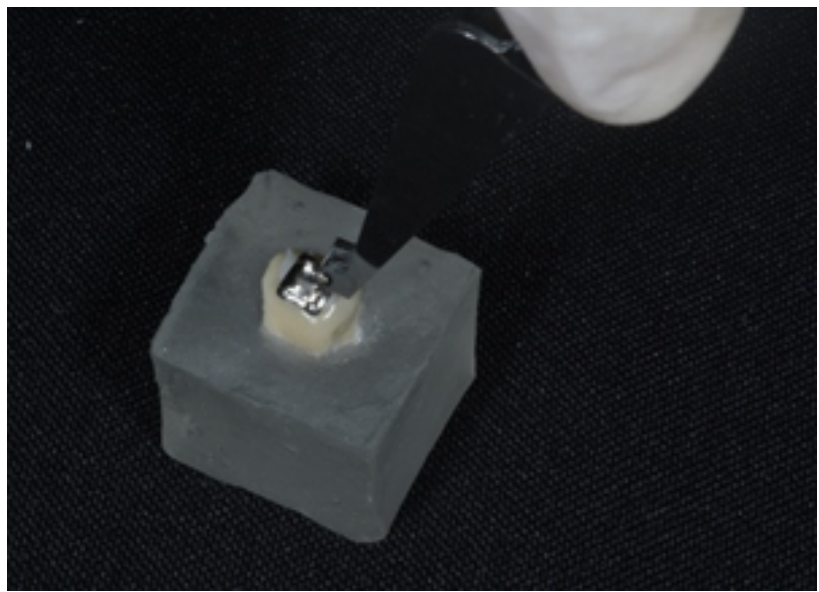

Figura 15 - Cimentação dos bráquetes com resina fotopolimerizável.

\section{Fotopolimerização}

A fotopolimerização foi realizada com lâmpada de luz alógena (Optilux 400), por 20 segundos (Figura 16), em todos os grupos da amostra.

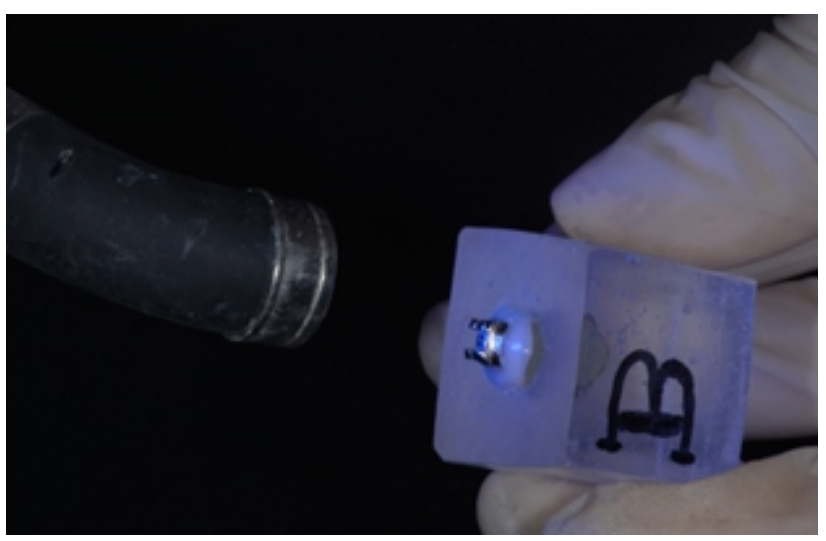

Figura 16 - Polimerização com lâmpada de luz alógena.

\section{Teste de Cisalhamento}

Após a preparação, as amostras foram levadas para a máquina de testes Universal (DL500 - EMIC) do Laboratório da escola Politécnica Nacional do Equador, e foram submetidas a forças progressivas medidas em Newton de força por milímetro quadrado (Figura 17), para registrar o deslocamento do bráquete e desta maneira determinar qual dos métodos de ataque ácido produz melhores efeitos de resistência ao cisalhamento. 

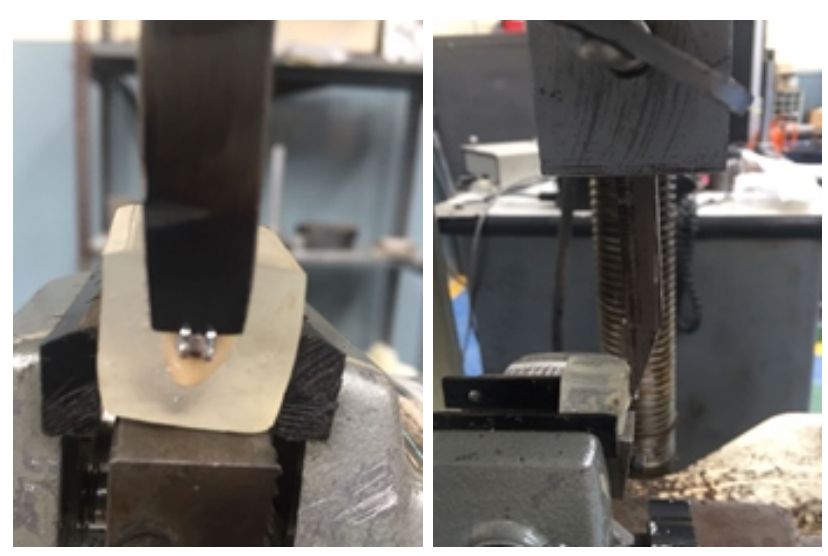

Figura 17 - Teste de cisalhamento.

As etapas de preparação das amostras estão demostradas na Figura 18.

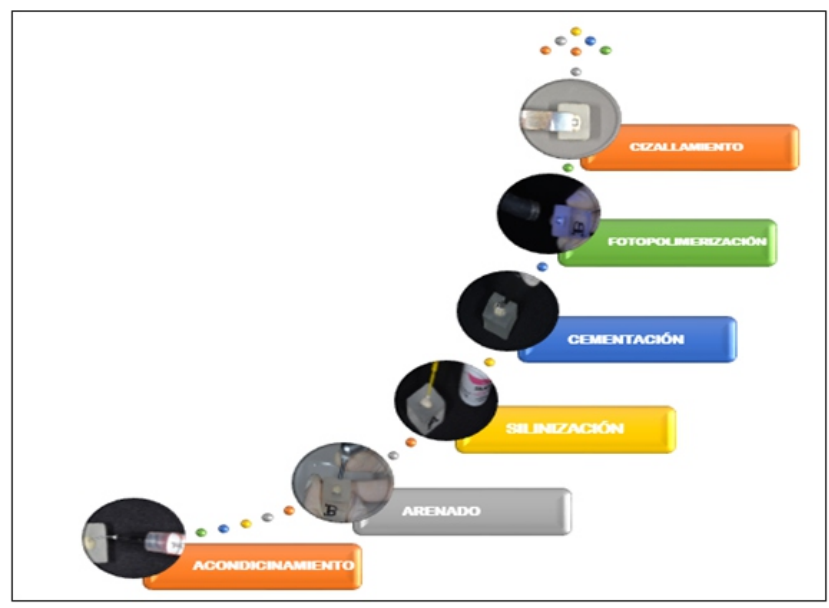

Figura 18 - Protocolo para colagem de bráquetes.

Os trinta blocos de resina acrílica, já preparados foram identificados (Figura 19) e enviados ao Laboratório de Análises de Esforço e Vibração da Escola Politécnica Nacional do Equador com o objetivo de realizar os testes de cisalhamento para medir o grau de retenção.

\begin{tabular}{|c|c|}
\hline Amostra & Identificação LAEV \\
\hline Grupo A & Ga \\
\hline Grupo B & Gb \\
\hline
\end{tabular}

Figura 19 - Identificação das amostras.

Os dados do teste de cisalhamento para cada grupo foram introduzidos em uma base de dados nos programas SPSS (IBM versão 22), a fim de realizar os cálculos em estatísticas descritivas e inferenciais.

\section{RESULTADOS}

O teste de cisalhamento foi calculado de acordo com o tipo de material odontológico utilizado para o condicionamento ácido, levando-se em conta a carga máxima registrada e a área de incidência do bráquete. $\mathrm{O}$ cálculo foi realizado em unidades de pressão $(\mathrm{Pa})$, ou seja, a pressão exercendo uma força de 1 Newton na superfície de um metro quadrado, utilizando a unidade em Megapascal (MPa). Os resultados são apresentados nas Figuras 20, 21, 22 e 23.

\section{Resultados do Grupo A}

\begin{tabular}{|c|c|c|c|c|c|}
\hline \multirow[t]{2}{*}{ Id. } & $\begin{array}{c}\text { Carga } \\
\text { máxima } \\
\text { registrada }\end{array}$ & $\begin{array}{c}\text { Comprimento } \\
\text { nominal } 2\end{array}$ & $\begin{array}{c}\text { Comprimento } \\
\text { nominal } 2\end{array}$ & $\begin{array}{c}\text { Área } \\
\text { Nominal }\end{array}$ & $\begin{array}{c}\text { Teste de } \\
\text { cisalhamento }\end{array}$ \\
\hline & $\mathbf{N}$ & $\mathrm{mm}$ & $\mathrm{mm}$ & $\mathrm{mm}^{\wedge} 2$ & Mpa \\
\hline GA-1 & 156.42 & 4.06 & 3.79 & 15.39 & 10.17 \\
\hline GA-2 & 157.64 & 4.06 & 3.79 & 15.39 & 10.24 \\
\hline GA-3 & 111.84 & 4.06 & 3.79 & 15.39 & 7.27 \\
\hline GA-4 & 178.06 & 4.06 & 3.79 & 15.39 & 11.57 \\
\hline GA-5 & 165.69 & 4.06 & 3.79 & 15.39 & 10.77 \\
\hline GA-6 & 141.12 & 4.06 & 3.79 & 15.39 & 9.17 \\
\hline GA-7 & 146.17 & 4.06 & 3.79 & 15.39 & 9.50 \\
\hline GA-8 & 152.98 & 4.06 & 3.79 & 15.39 & 9.94 \\
\hline GA-9 & 131.46 & 4.06 & 3.79 & 15.39 & 8.54 \\
\hline GA-10 & 184.5 & 4.06 & 3.79 & 15.39 & 11.99 \\
\hline GA-11 & 190.77 & 4.06 & 3.79 & 15.39 & 12.40 \\
\hline GA-12 & 132.53 & 4.06 & 3.79 & 15.39 & 8.61 \\
\hline GA-13 & 139.6 & 4.06 & 3.79 & 15.39 & 9.07 \\
\hline GA-14 & 168.78 & 4.06 & 3.79 & 15.39 & 10.97 \\
\hline \multirow[t]{5}{*}{ GA-15 } & 142.07 & 4.06 & 3.79 & 15.39 & 9.23 \\
\hline & & & \multirow{2}{*}{\multicolumn{2}{|c|}{ Média }} & 9.96 \\
\hline & & & Desvio padrão & & 1.41 \\
\hline & & & \multicolumn{2}{|c|}{ Valor Mínimo } & 7.27 \\
\hline & & & \multicolumn{2}{|c|}{ Valor Máximo } & 12.40 \\
\hline
\end{tabular}

Figura 20 - Resultados da resistência de adesão do Grupo A.

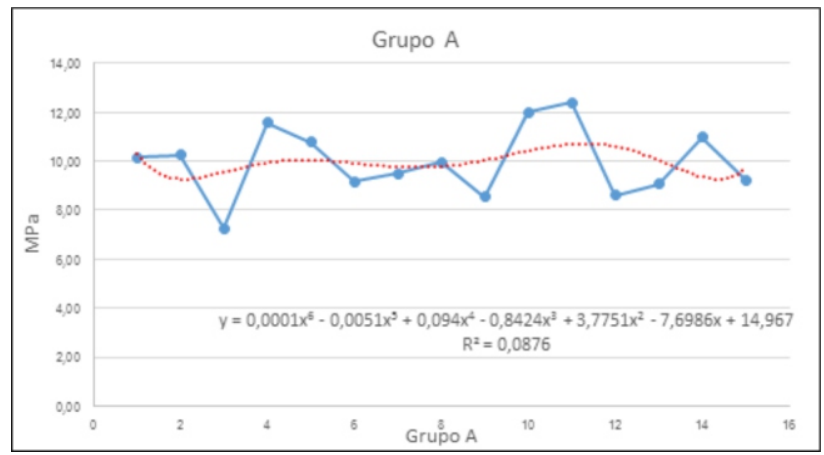

Figura 21 - Variação da resistência a adesão para o Grupo A. 


\section{Resultados do Grupo B}

\begin{tabular}{|c|c|c|c|c|c|}
\hline \multirow[t]{2}{*}{ Id. } & $\begin{array}{c}\text { Carga } \\
\text { máxima } \\
\text { registrada }\end{array}$ & $\begin{array}{c}\text { Comprimento } \\
\text { nominal } 2\end{array}$ & $\begin{array}{c}\text { Comprimento } \\
\text { nominal } 2\end{array}$ & $\begin{array}{c}\text { Área } \\
\text { Nominal }\end{array}$ & $\begin{array}{c}\text { Teste de } \\
\text { cisalhamento }\end{array}$ \\
\hline & $\mathbf{N}$ & $\mathrm{mm}$ & $\mathrm{mm}$ & $\mathrm{mm}^{\wedge} 2$ & Mpa \\
\hline GB-1 & 135.41 & 4.06 & 3.79 & 15.39 & 8.80 \\
\hline GB-2 & 131.68 & 4.06 & 3.79 & 15.39 & 8.56 \\
\hline GB-3 & 187.55 & 4.06 & 3.79 & 15.39 & 12.19 \\
\hline GB-4 & 113.34 & 4.06 & 3.79 & 15.39 & 7.37 \\
\hline GB-5 & 166.88 & 4.06 & 3.79 & 15.39 & 10.85 \\
\hline GB-6 & 235.67 & 4.06 & 3.79 & 15.39 & 15.32 \\
\hline GB-7 & 133.21 & 4.06 & 3.79 & 15.39 & 8.66 \\
\hline GB-8 & 252.61 & 4.06 & 3.79 & 15.39 & 16.42 \\
\hline GB-9 & 192.01 & 4.06 & 3.79 & 15.39 & 12.48 \\
\hline GB-10 & 201.27 & 4.06 & 3.79 & 15.39 & 13.08 \\
\hline GB-11 & 95.99 & 4.06 & 3.79 & 15.39 & 6.24 \\
\hline GB-12 & 110.63 & 4.06 & 3.79 & 15.39 & 7.19 \\
\hline GB-13 & 82.7 & 4.06 & 3.79 & 15.39 & 5.37 \\
\hline GB-14 & 79.82 & 4.06 & 3.79 & 15.39 & 5.19 \\
\hline GB-15 & 95.57 & 4.06 & 3.79 & 15.39 & 6.28 \\
\hline & & & & Média & 9.60 \\
\hline & & & $\mathrm{De}$ & svio padrão & 3.59 \\
\hline & & & & alor Mínimo & 5.19 \\
\hline & & & & lor Máximo & 16.42 \\
\hline
\end{tabular}

Figura 22 - Resultados da resistência de adesão do Grupo B.

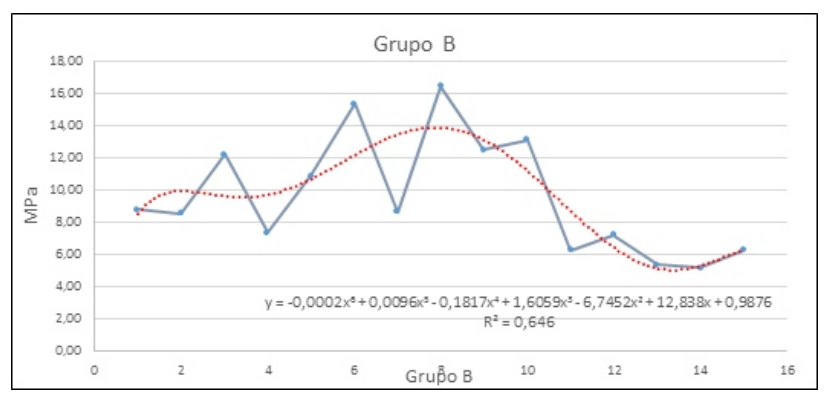

Figura 23 - Variação da resistência a adesão para o Grupo B.

\section{Comparação Entre os Grupos}

A comprovação começa ao verificar se não existem valores extremos, de acordo com o método de Tukey, que se refere à diferença entre o primeiro quartil (Q1) e o terceiro quartil (Q3), chamado de intervalo interquartil, o mesmo que pode ser obtido por diferentes circunstâncias. Esta variação foi observada no gráfico bloxpot (Figura 24).

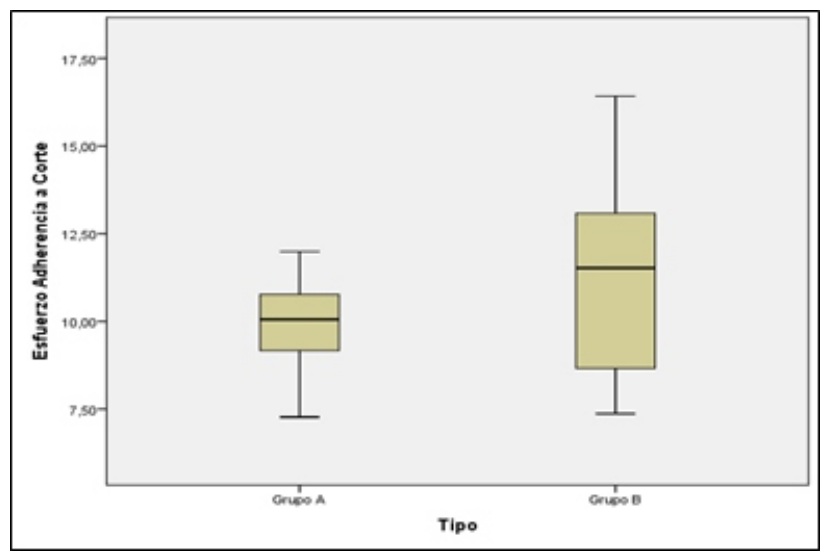

Figura 24 - Gráfico em boxplot dos Grupos A e B.
Como se pode observar, não existem valores atípicos para todos os grupos. A estatística descritiva deve, portanto, ser analisada de acordo com os valores do teste de cisalhamento.

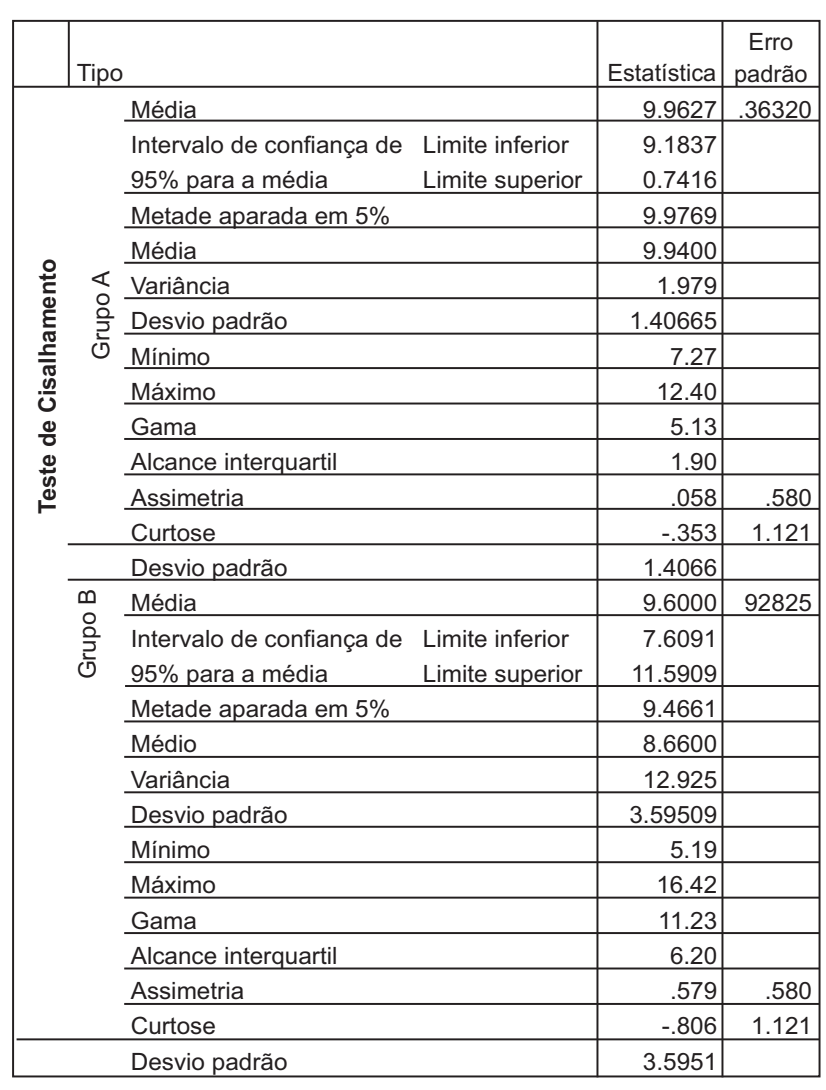

Figura 25 - Resultados da resistência de adesão aos Grupos A e B.

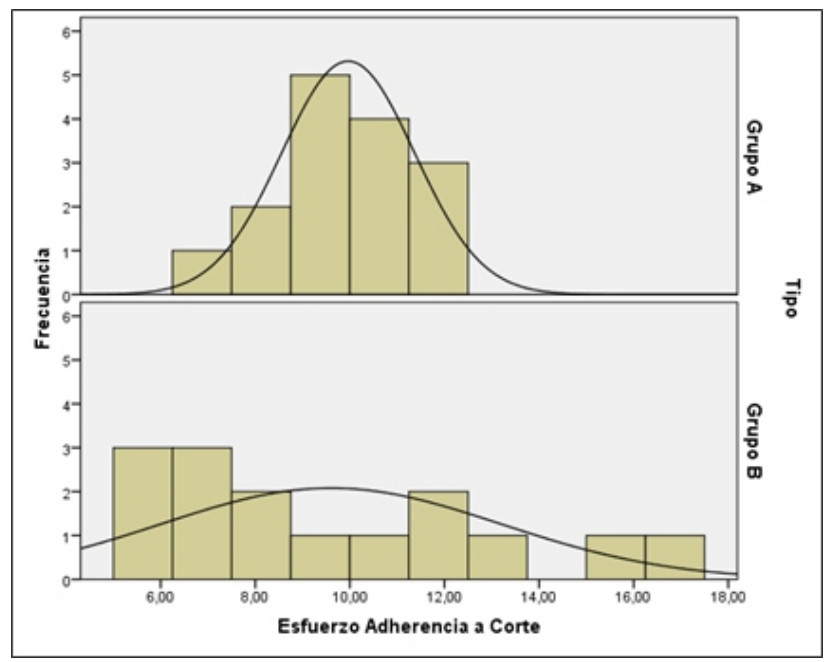

Figura 26 - Histograma de dados dos Grupos A e B. 
As Figuras 25 e 26 mostram as estatísticas sumárias do Grupo A e do Grupo B que incluem medidas de tendência central.

Grupo A: A amostra tem uma média de $9.96 \mathrm{Mpa}$, com desvio padrão de $1.40 \mathrm{Mpa}$.

Grupo B: A amostra tem uma média de $9.6 \mathrm{Mpa}$, com desvio padrão de $3.59 \mathrm{Mpa}$.

De acordo com a análise é um estudo transversal porque está sendo analisado variáveis fixas em dois grupos em um mesmo momento e a variável aleatória são valores numéricos. Portanto, de acordo com o quadro (Figura 27) de eleição, será selecionado o teste $\mathrm{T}$ de Student para amostras independentes.

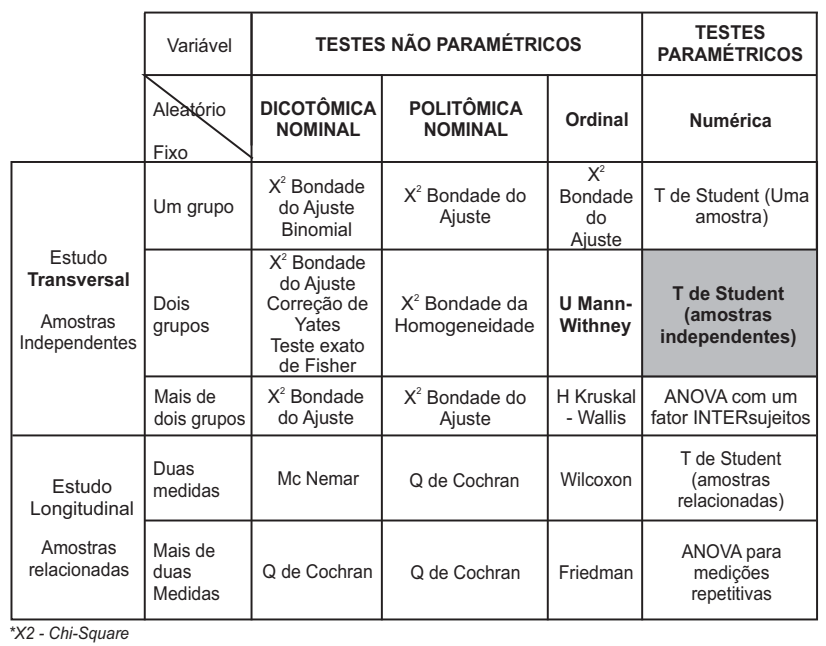

Figura 27 - Quadro de seleção estatística Grupo Ae B.

Antes de realizar o teste estatístico T de Student, deve começar realizando um teste de normalidade (Figura 28). Deve-se verificar se a variável aleatória é normalmente distribuída, para isso o teste SHAPIRO-WILK, que é escolhido como é eficaz quando o tamanho da amostra é menor ou igual a 30 .

Ho: Amostras vêm de populações com distribuição normal.

Ha: As amostras não vêm de populações com distribuição normal.

\begin{tabular}{|l|l|r|r|r|r|r|r|}
\hline & \multirow{3}{*}{} & \multicolumn{3}{|c|}{ kolmogorov-Smirnov } & \multicolumn{3}{|c|}{ Shapiro-Wilk } \\
\cline { 2 - 8 } & Tipo & Estatística & gl & Sig. & Estatística & gl & Sig. \\
\hline Cisalhamento & Grupo A & .099 & 15 & $200^{*}$ & .981 & 15 & .974 \\
& Grupo B & .188 & 15 & $.161 *$ & .925 & 15 & .231 \\
\hline
\end{tabular}

Este é o limite inferior de verdadeiro significado.

a. Correção de Lilliefors.

Figura 28 - Teste de normalidade.

A partir do teste de normalidade é determinado que todos os grupos A e B vêm de uma população com distribuição normal, pois excedem o nível de significância imposto por 0.05 (Figura 29).

\begin{tabular}{|l|c|l|}
\hline P-Valor GA $=0.974$ & $>$ & 0.05 \\
\hline P-Valor GB $=0.231$ & $>$ & 0.05 \\
\hline
\end{tabular} $\begin{aligned} & \text { Conclusão: A variável de estresse de adesão ao corte } \\
& \text { para os grupos A e B se comporta normalmente (Ho). }\end{aligned}$

Figura 29 - Teste de normalidade.

Uma vez que os grupos tenham confirmado as distribuições normais, é definido o resultado do teste $\mathrm{T}$ Student (Figura 30) para amostras independentes.

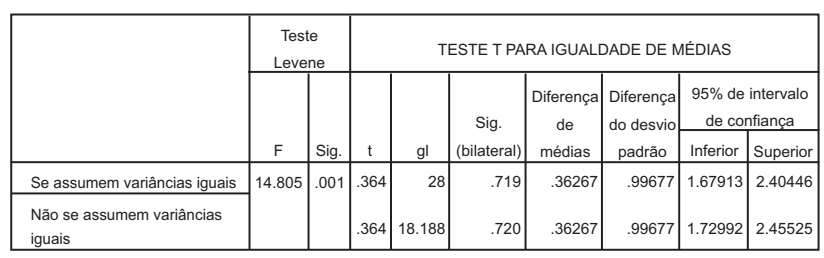

Figura 30 - Teste T Student para amostras independentes.

Em primeiro lugar, começamos a avaliar a partir da igualdade de variância (Figura 31) onde deve ser considerado se há ou não variâncias iguais entre os dois grupos:

Ho: As variâncias dos grupos A e B são as mesmas.

Ha: Há uma diferença significativa entre as variâncias dos dois grupos.

\begin{tabular}{|l|c|l|}
\hline P-Valor $=0.001$ & $<$ & 0.05 \\
\hline Conclusão: Não são assumidas variâncias iguais. \\
\hline
\end{tabular}

Figura 31 - Igualdade de variância.

A seguinte hipótese é imposta para o critério final do teste T Student (Figuras 32 e 33):

Ho: Não há diferença significativa entre as médias do teste de cisalhamento das amostras do Grupo Ae do Grupo B.

Ha: Há uma diferença significativa entre as médias do teste de cisalhamento das amostras do Grupo A e do Grupo B.

\begin{tabular}{|l|c|l|}
\hline P-Valor $=0.720$ & $>$ & 0.05 \\
\hline $\begin{array}{l}\text { Conclusão: Não há diferença significativa entre o cisalhamento } \\
\text { médio de adesão ao corte das amostras do Grupo A e do Grupo B. }\end{array}$ \\
\hline
\end{tabular}

Figura 32 - Teste T Student. 


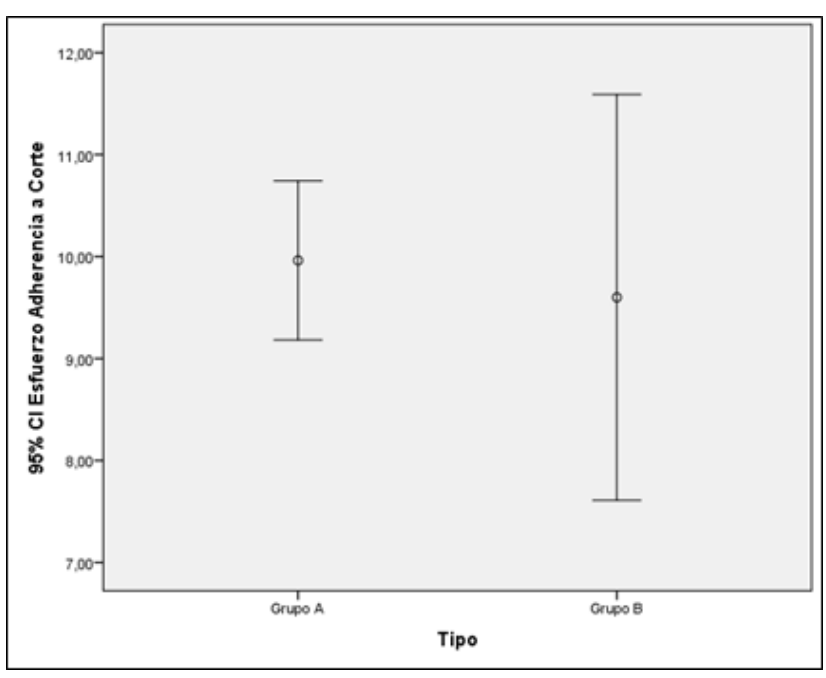

Figura 33 - Gráfico de médias do Grupo A e B.

\section{DISCUSSÃO}

No presente estudo foi observado que, para obter resistência de união entre a cerâmica feldspática e os bráquetes é importante a utilização de ácido fluorídrico associado com silano como agente de união no tratamento da superfície da porcelana, assim foi confirmado os resultados de estudos de teste de resistência as forças de cisalhamento, realizados por vários autores ${ }^{6,9,17-19,24}$.

A partir da revisão de literatura sobre o tema, todos os autores utilizam ácido fluorídrico em diferentes concentrações entre $4 \%$ a $10 \%$, e para compará-los com outras técnicas mecânicas e químicas, como o ácido fosfórico em $37 \%$. A conclusão geral é que os dois tipos de ácidos geram retenção semelhante, mas por apresentar menor toxicidade nos tecidos moles do paciente, a maioria dos autores, recomenda o ácido fosfórico. No entanto, a melhor retenção dos bráquetes é com ácido fluorídrico em $9 \%$ e $9.6 \%$ de concentração. De acordo com as conclusões dos autores, o percentual de concentração do ácido fluorídrico não apresenta relevância na resistência do bráquetes colado na porcelana feldspática, os resultados deste estudo corroboram com os resultados desta pesquisa. No entanto, deve-se notar que essas diferentes porcentagens têm reação diferente de acordo com o tipo de porcelana utilizada em próteses fixas ${ }^{19}$.

Considerando que o tempo de condicionamento é um fator decisivo para alcançar a resistência de união dos bráquetes à porcelana feldspato, ${ }^{9,17-19}$, a melhor retenção é obtida com ácido fluorídrico de $9 \%$ durante 60 segundos de condicionamento. Assim, analisando os tempos mínimos ${ }^{6}$, utilizando HF de $4.6 \%$ por 20 segundos $^{24}$ e utilizando HF de $9.5 \%$ por 30 segundos, tiveram melhores resultados, mas há controvérsias com os resultados ${ }^{27}$, onde mostra que a diminuição dos tempos de condicionamento pode afetar não só a resistência à união, mas também o modo de falha do material de união.

Relatou-se que o condicionamento ácido mais de 60 segundos é excessivo, e altera a porcelana com a completa dissolução da matriz vítrea ${ }^{9}$. Outros estudos ${ }^{10-12}$ apesar de apresentarem testes convencionais de resistência ao cisalhamento confirmam o efeito da concentração e do tempo de aplicação do ácido fluorídrico nos valores de adesão ao material resinoso. Onde, na maior concentração e tempo de aplicação, há uma tendência de diminuir os valores de adesão a esse tipo de material.

Os resultados obtidos em estudos onde os autores realizaram teste de cisalhamento para medir a força de adesão na retenção dos bráquetes à porcelana concluem que uma força de união adequada é de 6 a $8 \mathrm{Mpa}$ (Megapascal) ${ }^{8}$, determina que o HF em $9.6 \%$ associado ao silano obteve $7 \mathrm{Mpa}^{20}$, obtiveram valores de $9.42 \mathrm{Mpa}^{15}$, valores de 9.03 $\mathrm{Mpa}^{14}$, valores de $9.03 \mathrm{Mpa}$, e também teve resultados de $5.06 \mathrm{MPa}$ com HF de $5 \%$ por 120 segundos ou 2 minutos, os valores acima mencionados estão dentro da faixa de valores obtidos neste estudo ${ }^{17}$.

Outro estudo afirma que não existe relevância quando utilizado o ácido fluorídrico aos bráquetes cerâmicos ou metálicos no procedimento ${ }^{3}$.

Há uma melhor retenção quando o processo de jateamento com óxido de alumínio é realizado na superfície da porcelana feldspato, especificamente quando atinge o glaze da porcelana ${ }^{25}$.

O resultado da pesquisa demonstra que o condicionamento do ácido fluorídrico à superfície da porcelana feldspática com uma concentração de 5\% e 10\% pelo tempo de 2 minutos, não tem diferença significativa de acordo com a os resultados, uma vez que o valor médio é de 9.96 Mpa e 9.6 Mpa, respectivamente.

\section{CONCLUSÃO}

A partir da pesquisa realizada para conhecer os efeitos das duas concentrações de ácido fluorídrico de 5 e $10 \%$ no condicionamento ácido para porcelana feldspática, o resultado é que não houve diferença significativa para a adesão aos bráquetes metálicos, considera-se importante $o$ tempo de condicionamento de 2 minutos.

Recomenda-se utilizar o ácido de menor concentração (5\%), por 2 minuto, a fim de minimizar o possível risco aos tecidos moles do paciente. 


\section{REFERÊNCIAS}

1. Stella JPF. Four chemical methods of porcelain conditioning and their influence over bond strength and surface integrity. Dent Press J Orthod. 2015;20(4):51-6.

2. Zachrisson $Y \varnothing$, Zachrisson BU, Büyükyilmaz T. Surface preparation for orthodontic bonding to porcelain. Am J Orthod Dentofac Orthop. 1996;109(4):420-30.

3. Al-Hity R, Gustin, M-P, Bridel N, Morgon, L, Grosgogeat B. In vitro orthodontic bracket bonding to porcelain. Eur J Orthod. 2012 Aug;34(4):505-11.

4. Álvarez-Fernández M. Características generales y propiedades de las cerámicas sin metal. Rcoe. 2003;8(5):525-46.

5. Uso del ácido fluorhídrico [Internet]. València: Universitat de València; 2017 [cited 2017]. Available from: : https://www.uv.es/preven/recursos/preguntes/protocols/protocol_us _acid_fluorhidric_sp.pdf

6. Caparroso-Pérez C, Mejia Bravo, R, Sosa Villa, JF, Mazo Escobar AM. Evaluación in vitro del efecto de la concentración y el tiempo de aplicación del ácido fluorhídrico sobre la resistencia a la flexión biaxial y la rugosidad del disilicato de litio de última generación. Int $\mathrm{J}$ Odontostomatology. 2015;9(2):273-81.

7. Callister WD. Introducción a la ciencia e ingeniería de los materiales. Barcelona: Reverté; 1995.

8. Alvarez NC. Estudio comparativo entre dos sustancias, ácido orto fosfórico al 35\% y el ácido fluorhídrico al 9\%, sobre porcelana visualizada al MEB (microscopio electrónico de barrido) [monograph]. Guayaquil: Universidad de Guayaquil; 2017.

9. Guzmán-Thoms JP; González-Bustamante H, Salgado-Montoya M. Influencia del tiempo de tratamiento de superficie con ácido fluorhídrico de la porcelana VITA VM 13 en la resistencia de unión a cemento de resina frente a fuerzas de tracción: estudio in vitro. Rev Clin Period, Implantol Rehab Oral. 2012;5(3):117-21.

10. Kiyan VH. The influence of internal surface treatments on tensile bond strength for two ceramic systems. Oper Dent. 2007;32(5):457-65.

11. Goekce B. Bond strengths of all-ceramics: acid vs laser etching. Oper Dent. 2007;32(2):173-8.

12. Kim BK. The influence of ceramic surface treatments on the tensile bond strength of composite resin to all-ceramic coping materials. J Prosth Dent. 2005;94(4):357-62.

13. Mehta AS. Bonding of metal orthodontic attachments to sandblasted porcelain and zirconia surfaces. Biomed Res Int. 2016.

14. Mokhtarpour F, Alaghehmand H, Khafri S. Effect of hydrofluoric acid surface treatments on micro-shear bond strength of CAD/CAM ceramics. Electr Phys. 2017;9(10):5487.

15. Alanuca-Chumbi C, Chumi R. Adhesión de brackets a porcelana. Rev Latinoam Ortod Odontopediatr [Internet]. $2015 \mathrm{Jul}$ [cited $2015 \mathrm{Jul}$ 31]. Available from: https://www.ortodoncia.ws/publicaciones/2015/art-24/

16. Sabuncuoglu FA, Erturk E. Shear bond strength of brackets bonded to porcelain surface: in vitro study. J Istanb Univ Fac Dent. 2016;50(1):9.

17 Cruz FO. Efecto de la aplicación de diferentes ácidos fluorhídricos en la resistencia adhesiva sobre una cerámica feldespática. Oral. 2011;12(38):734-8.

18. Gonçalves PRA Effect of etching time and light source on the bond strength of metallic brackets to ceramic. Braz Dent J. 2011;22(3):245-8

19. Castro-Hoyle JM; Málaga-Rivera JA. Rugosidad en la superficie de cerámicas feldespáticas, empleando dos tipos de agente grabador. KIRU. 2013;10(2):101-6.

20. Ballesteros-Pinzón C, Bermudéz Lozano JA, Coronel Corzo N, de León Goenaga E, Delgado LP, Báez Quintero L. Comparación de la fuerza de adhesión de brackets utilizando dos métodos de acondicionamientopara porcelana. Rev Nac Odont. 2014;7(13):12-9.

21. Abu Alhaija ES, Abu AlReesh IA, Alwahadni AMS. Factors affecting the shear bond strength of metal and ceramic brackets bonded to different ceramic surfaces. Eur J Orthod. 2010 Jun;32(3):274-80.

22. Grewal-Bach GK, Torrealba Y, Lagravère MO. Orthodontic bonding to porcelain: a systematic review. Angle Orthod. 2014;84(3):555-60.

23. Trakyali G. Effects of different silanes and acid concentrations on bond strength of brackets to porcelain surfaces. Eur J Orthod. 2009;31(4):402-6.

24. Nagayassu MP. Effect of surface treatment on the shear bond strength of a resin-based cement to porcelain. Braz Dent J. 2006;17(4):290-5.

25. Kato $\mathrm{H}$, Matsumura $\mathrm{H}$, Atsuta $\mathrm{M}$. Effect of etching and sandblasting on bond strength to sintered porcelain of unfilled resin. J Oral Rehab. 2000;27(2):103-10.

26. Santos LR. O ácido fluorídrico na resistência ao cisalhamento entre cerâmica feldspática e resina composta. Rev Assoc Paul Cir Dent. 2015;69(1):62-7.

27. Olsen ME. Effect of varying etching times on the bond strength of ceramic brackets. Am J Orthod Dentofac Orthop. 1996;109(4):403-9. 